\title{
CLINICAL FINDINGS AND MANAGEMENT OF HERPECTIC KERATOUVEITIS WITH SECONDARY GLAUCOMA (A CASE REPORT)
}

\author{
BY \\ *UDOM, U. C. AND IDU, F. K. \\ *CEEJAY VISION CENTRE, 7 EKPO OBOT STREET, \\ UYO, AKWA IBOM STATE, NIGERIA \\ Email: evac1788@yahoo.com
}

\begin{abstract}
Inflammation of the iris and ciliary body, referred to as anterior uveitis, occurs frequently with herpes zoster ophthalmicus. And may be isolated or associated with keratitis, an inflammation of the cornea. When associated with keratitis, it is referred to as Keratouveitis. Herpes zoster is a common infection caused by the human herpes virus 3 when reactivation of the latent virus in the trigeminal ganglia involves the ophthalmic division of the nerve. The virus damages the eye and surrounding structures by secondary perineural and intraneural inflammation of sensory nerves. Ocular complications sometimes ocular pressure (IOP) may be elevated as a result of altered or obstructed aqueous outflow, leading to uveitic glaucoma, with IOP ranging from 30 to $80 \mathrm{Hg}$. The following case report is a review of clinical findings and management of herpetic keratouveitis with secondary glaucoma in a 62-year-old black male, who had no facial rash.
\end{abstract}

KEYWORDS: Herpes zoster, Uveitis, Glaucoma, Keratitis, Keratouveitis

\section{INTRODUCTION}

Anterior Uveitis is one of the most common forms of ocular inflammation often causing a painful red eye ${ }^{1}$. Although uveitis beginning in patients 60 years of age or older is relatively uncommon, the incidence of certain forms of uveitis increase with age, and one commonly recognized cause of uveitis in this population is herpes zoster ophthalmicus $(\mathrm{HZO})^{2,3}$. Herpes zoster is a common infection caused by the human herpes virus3, (the same virus that causes varicellachickenpox), when reactivation of latent virus (acquired during childhood) in the trigeminal ganglia involves the ophthalmic division of the nerve $^{2,4,5}$. It may become active as a result of many factors such as: aging, stress, suppression of the immune system, and certain medications. Primary infection is a vesicular rash over face, trunk, and/or extremities.

The virus damages the eye and surrounding structures by secondary perineural and intraneural inflammation of sensory nerves ${ }^{6,7}$. The vesicular skin rash usually appears about five days after pains and general malaise, along the distribution of the fifth cranial nerve, characteristically respecting the vertical midline ${ }^{5,8-10}$. A minority of patents with herpes zoster may have only ophthalmic findings ${ }^{4,9}$. The ocular involvements may occur in some cases even when there is zoster rash remote from the eye $\mathrm{e}^{9,10,11}$.
The varicella zoster virus may penetrate the ocular tissues to cause numerous complications and, in some cases, masquerade other ocular diseases. The inflammatory reaction can occur in any portion of the eye or adnexal tissue. Ocular involvement of herpes zoster includes lid erythema, punctuate epithelial keratitis, stromal keratitis, neurogenic hyposecretion and dry eye, follicular conjunctivitis, episcleritis, scleritis, uveitis, iritis, retinal necrosis, secondary glaucoma, optic neuritis and optic atrophy ${ }^{4-8,11-13}$.

\section{CASE REPORT}

PE, a 61-year old black male, university lecturer presented in our clinic on January $26^{\text {th }}$ 2004, complaining of blurred vision, tearing, photophobia, foreign body sensation and redness in the right eye for one week, following feelings of general body pains, weakness and headache two weeks earlier. Ocular history included pterygium excision on the right eye in 1992, and using bifocal glasses since 1986. Present glasses were obtained during his last eye examination in 2001, but he was not told he had any pathological condition at the time. He denied having any previous episodes of the present condition. He had used chloramphenicol eye drops for 5 days, but symptoms persisted, and vision was deteriorating.

On his family ocular history, only know that one of his brothers used reading glasses. His medical 
history was that of hypertension controlled with oral medications for 2 years. He also remembered having chicken pox as a child. He had rashes on one side of his trunk, which he attributed to the hot weather, as he often has heat rash in the dry season. On questioning about the size of the heat rash, he admitted they were not tiny rash. He reported that he had been very busy the previous month. Family medical history showed that his elder brother has hypertension. Drug history included Hydralazine and Nifedipine tablets. He also takes periodic antimalarial ï Maloxine every two months. Last antimalarial treatment he took with analgesics and antibiotics (Novalgin and Amoxil) was two weeks earlier, when he had symptoms of general malaise and severe headache. He had no known allergies.

\section{CLINICALFINDINGS}

PE's ocular examination revealed the following: Uncorrected Distance Visual Acuity: $\quad$ OD 6/18, OS 6/12 Uncorrected Near Visual Acuity: ODN48, OS N36 VA with old glasses: OD distance 6/12, near N8: OS distance 6/9, near N5.

Old Rx +0.50 Add 2.00, obtained in Feb. 2001.

External ocular examination with penlight and magnifiers revealed

OD: Swollen eyelids, watery discharge, photophobia, steamy cornea, brown iris and perilimbal injection. Pupil was irregular, miotic and sluggish. Keratitic precipitates were seen in the anterior chamber. fluorescein staining was negative

OS: Cornea and conjunctiva were clear, with no discharge, pupil was round, reacting to light.

OU: EOMs were normal and full in all gazes. Confrontations were full to finger counting, but Amsler grid revealed mild superior arcuate scotoma, with a few central wavy lines, OD. Anterior chamber depth was grade 3+. Intraocular pressure (IOP) measurements with Schiotz tonometer were OD $38.8 \mathrm{mmHg}$, OS $25.8 \mathrm{mmHg}$ at $12.45 \mathrm{pm}$. PE's blood pressure was 134/92.

Ophthalmoscopy findings (pupils dilated with $1 \%$ Mydriacyl) showed OU; clear lens and vitreous, optic disc appeared pink, vertical oval, with distinct disc margins and a physiological cupping, cup-to-disc ratio was 0.4 and depth of cup was 2.00D. Spontaneous venous pulsation was present. Arterial-venous ratio 1:2 (showing arterial attenuation) and $\mathrm{A} / \mathrm{V}$ crossing showed mild compression of venules. Course of retinal vessels was mildly tortuous. Retina had few drusen.
Nothing remarkable was found on the posterior pole.

OD: Retina was slightly raised at the macula; foveal reflex was absent and faint.

OS: Retina was flat.

\section{DIAGNOSIS}

*Anterior Uveitis with secondary glaucoma

*Herpes Simplex type 1 (Herpes Zoster ophthalmicus)

\section{PATIENT TREATMENT AND REFERRAL}

Prescription given was:

- $1 \%$ Mydriacyl, tds, OD x $1 / 52$ to dilate the pupil so the inflamed ciliary body would rest and prevent both anterior and posterior synachae.

- Tabs Ibuprofen $400 \mathrm{mg}$ tds x 5/7 to reduce pain

- Gutt $0.5 \%$ Timoptol bds, OD x 2/52 and Tabs

Diamox 250mg tds x $3 / 7$ to reduce intraocular pressure.

- Gutt Efemoline one drop 1/2 hourly first day. Then taper to quarter hourly, OD x $1 / 52$ to reduce inflammation.

\section{Check-up in 2 days}

PE's physician certified that he could take acetazolamide (Diamox) with the antihypertensive he was taking.

\section{Follow -up visit: Jan 28, 2004}

$\mathrm{PE}$ returned to clinic in 2 days, and findings on examination were as follows:

VA (unaided) OD: 6/12, OS: 6/12. Cornea was clearer. Conjunctival injection was beginning to resolve. IOP measurements with the Schiotz tonometer: OD: $24.4 \mathrm{mmHg}$ OS: $17.3 \mathrm{mmHg}$ at $11.15 \mathrm{am}$. PE reported that he was feeling a lot better, the pains and FB sensation were subsiding. It was explained to PE that he was still to be referred to the ophthalmologist for expert management and advice. PE was then referred to see an ophthalmologist.

\section{Follow-up visit: Feb 16, 2004}

PE returned to the clinic nearly three weeks later, complaining of blurred vision for 2days. External ocular examination with penlight showed swollen upper eyelid with mild blepharoptosis, watery discharge, steamy cornea and perilimbal injection, OD. Cornea showed tapering dendrites, staining poorly with fluorescein. IOP measurements with the Schiotz tonometers were OD: $30: 4 \mathrm{mmHg}$, OS: 
$25.8 \mathrm{mmHg}$ at $10.30 \mathrm{am}$.

On questioning PE he admitted he had not gone to see the ophthalmologist, since he was felling fine. So he had just continued with the medication he had obtained previously. He was encouraged to see his ophthalmologist. No further medication was prescribed.

Information formation from the referral hospital was as follows:

On March $16^{\text {th }} 2004$, PE was treated with:

Gutt Timoptol bd, OD

GuttEfemoline qds, OD

Gutt Azopt bd, OD

Gutt mydriacy $1 \%$ tds, OD (Duration of use for these drugs was not indicated on the patient's card). Zovirax 800mg 5 times dly x $1 / 52$

Tabs paracetatamol ii tds $\times 5 / 7$

Tabs lexotan $1.5 \mathrm{mg}$ bd x 5/7

There was no record in his file of any laboratory work up. He was reviewed every week, but continued on the same topical medication. He was sent for visual fields test on March 30, and continued only on Timoptol and Azopt. He was finally admitted for trabeculectomy on May $3^{\text {rd }}$ 2004; which was done on May $5^{\text {th }}$ 2004, OD; and on May $6^{\text {th }} 2004$, OS.

\section{Follow up Visit: August $16^{\text {th }} 2004$}

$P E$ returned to the clinic for new glasses.

-PE's unaided VA was OD: 6/18. OS: 6/9

-External ocular examination with penlight showed cornea clear. Conjunctiva clear with diffuse blebs and pupils round, mid dilated and active, OU. Media were clear, OU.

-Ophthalmoscopy showed same findings as last seen, with scanty vitreous floaters, OD.

-IOPOD: $10.2 \mathrm{mmHg}$, OS: $14.6 \mathrm{mmHg}$ at $13.10 \mathrm{am}$. -Refraction: OD +0.75/-0.50 x 85 VA 6/12; Add 2.25D VAN6

\section{VAN5}

OS +0.75/-0.50 x100 VA 6/6; Add 2.25D

\section{DISCUSSION}

Anterior uveitis, caused by herpes zoster, rarely occurs without corneal involvement; hence it usually occurs as keratouveitis ${ }^{4,5,10-13}$. Corneal involvement results in various degrees of pain, vision loss and photophobia. The earliest corneal finding is punctate epithelial keratitis ${ }^{14}$. On slit lamp examination, this appears as multiple, focal, swollen lesions that stain with Rose Bengal or fluorescein dye. These lesions probably contain live virus and may either resolve or progress to dendrite formation.

Punctate epithelial keratitis may present as early as one or two days after the initial skin rash, while dendrites often present at four to six days but can appear many weeks later ${ }^{15}$.

Glaucoma, as an ocular complication of herpes zoster, is secondary to uveitis. Iridocyclitis affects both aqueous production and resistance to aqueous outflow, with the subsequent change in IOP representing a balance between these two factors. Prostaglandins, which have been demonstrated to be present in the aqueous of eye with uveitis, also cause elevated IOP with a reduction in outflow facility. Mechanisms of increased resistance to aqueous outflow with both acute and subacute forms of uveitis usually are of the open-angle type and include obstruction of the trabecular meshwork by inflammatory cells or fibrin, swelling or dysfunction of the trabecular lamellae or endothelium, and inflammatory precipitates on the meshwork ${ }^{16-18}$.

The differentials diagnosis in PE's case is herpes simplex virus (HSV), which presents commonly as herpes dendritic keratitis. The patient with this condition usually presents with a unilaterally red eye, light sensitivity, pain, tearing, and decreased vision. A rash of the skin surrounding the eye may also be present. Patients with HSV tend to be younger than those with $\mathrm{HZO}$. The corneal epithelial findings demonstrate true terminal end bulbs, which stain well with fluorescein and Rose Bengal forming dendrites, which are destructive. The ñPseudodendritesò of HZO generally appear only on the epithelial layer and do not have true terminal end bulbs, stain poorly with fluorescein and do not etch the stromal tissue. Corneal ulcers do not develop from pseudodendritic HZO keratitis, but do with $\mathrm{HSV}^{19}$.

On PE's first visit, there was no facial rash so there was little or no suspicion of herpes. His selfpresentation two weeks later, this time, with corneal dendrites, began to throw more light on the condition. Then the 'heat rash' he had on a side of his trunk prior to his first visit became suspicious. In addition, the 'attack of malaria', before the heart rash began to appear like some other piece of the puzzle.

In PE's case, the self-administered drugs had probably masked some of the signs and symptoms of his condition. The chloramphenicol eye drops probably suppressed the early sign of punctate keratitis, while the analgesic and antibiotics 
masked or suppressed other signs and symptoms of his condition.

PE's IOP recordings remained between $39.3 \mathrm{mmHg}$ and $24.4 \mathrm{mmHg}$, OD, and between 24.4 and $14.6 \mathrm{mmHg}$, OS during the three months he was seeing the ophthalmologist. Visual fields test showed a superior arcuate scotoma, OD. A trabeculectomy was therefore decided on. The eyes appeared quiet during the last ocular examination.
There were no symptoms of post herpetic neuralgia, which affects about $7 \%$ HZO patients.

This is very typical case of masked signs and symptoms that many times lead to a wrong diagnosis, which in some cases, have resulted in very severe loss of vision, or even death. A very careful history therefore is indispensable. Interprofessional relationships are also extremely important.

\section{R E F E R E N C E S}

1. McCannel, C. A., Holland, G. N. and Helm, C. J. (1996): Causes of Uveitis in the general practice of ophthalmology. UCLA Community-based Uveitis Study Group. Am. J. Ophthalmol, 121(1): 35-46.

2. Cunningham, E. T. Jr. (2004): Uveitis in the elderly presents some unique challenges. Ophthalmol. Times, 1-5.

3. Rogers, R. S. and Tindall, J. P. (1971): Herpes zoster in the elderly. Postgrad. Med, 50(6): 153-7.

4. Saad Shaikh, C. N. (2002): Evaluation and Management of Herpes Zoster Ophthalmicus. Am. Fam. Physician, 66:1723-32.

5. Baratz, K. H., Goins, K. and Cobo, M. (1988): Varicella- zoter viral infections- The cornea. In: Kaufman HE, Edn. Churchhill Livingstone, New York, pp 123.

6. Naumann, G., Gass, J. D. and Font R. L. (1968): Histopathology of Herpes zoster ophthalmicus. Am. J. Ophthalmol, 65:533-41.

7. Ragozzino, M. W., Melton, L. J., Kurland, L. T., Chu, C. P. and Perry, H. O. (1982): Population-based study of herpes zoster and its sequelae. Med, 61:310-6.

8. Liesegang, T. J. (1991): Diagnosis and therapy of Herpes Zoster Ophthalmicus. Ophthalmol, 98(8): 1216-29.

9. Stawell, R. J. and Hall, A. J. H. (2002): Eye Signs in systemic disease. Aust. Fam. Physician, 217-23.

10. Huff, J. C., Bean, B., Balfour, H. H. Jr., Laskin, O. L., Connor, J. D. and Corey, L. (1988):
Therapy of herpes Zoster with oral acyclovir. Am. J. Med, 85:84-9.

11. Liesegang, T. J. (1997): Herpes Zoster keratities. In. Krachmer J.H., Mannis, M.J., Holland E.J. Edn. St. Louis Mosby, pp 273.

12. Harding, S. P., Lipton, J. R. and Wells. J. C. (1987): Natural history of herpes zoster ophthalmicus: predictors of postherpetic neuralgia and ocular involvement. Br. J. Ophthalmol, 71:353-8.

13. Heard, S. P. (1993): Management of ophthalmic zoster. J., Med. Virol. 1 (Suppl):97101.

14. Liesegang, T.J.(1985): Corneal complications from herpes zoster pohthalmicus. Ophthalmol, 92:316-24.

15. Jones, D. B. (1974): Herpes zoster ophthalmicus. In: Golden, B. Edn. Symposium on ocular inflammatory disease. Springfield III: Thomas, pp 7.

16. Herndon, L. W. (2000): Glaucoma associated with anterior uveitis. Current Ocular Ther, 5:470-1.

17. Kwon, Y. H. and Dreyer, E. B. (1996): Inflammatory glaucomas. Int. Ophthalmol. Clin, 36(1): 81-9.

18. Moorthy, R. S., Mermoud,A. and Baerveldt, G. (1997): Glaucoma associated with uveitis. Surv. Ophthalmol, 41(5): 361-94.

Chen, H. J., Pires, R. T. F. and Tseng, S. C. G. (2000): Amniotic membrane transplantation for severe neurotrophic corneal ulcers. Br. J. Ophthalmol, 84:826-33. 